\title{
Evolution of Geometric and Quality Features during Ultrasonic Vibration-Assisted Continuous Wave Laser Surface Drilling
}

\author{
S. Habib Alavi and Sandip P. Harimkar* \\ School of Mechanical and Aerospace Engineering, Oklahoma State University, \\ Stillwater, OK 74078, USA
}

\begin{abstract}
Recently, the processes involving simultaneous application of ultrasonic vibrations during conventional materials processing are attracting significant interests for improving process efficiency and material quality. It has been previously shown that the simultaneous application of ultrasonic vibrations (frequency of $20 \mathrm{kHz}$ and vibration displacement of $23 \mu \mathrm{m}$ ) during continuous wave $(\mathrm{CW}) \mathrm{CO}_{2}$ laser surface melting results in melt expulsion and formation of surface holes. In this paper, a systematic evolution of geometric features (hole depth, diameter, aspect ratio, and taper) and quality parameters (material build-up, spatter, recast layer thickness, and heat affected zone) of holes with laser irradiation time $(0.05,0.1,0.2,0.25,0.35,0.75$, and $1.25 \mathrm{~s}$ ) for the ultrasonic vibration-assisted $\mathrm{CW} \mathrm{CO}_{2}$ laser surface drilling of AISI 316 stainless steel is investigated. Also, a multi-step finite element analysis, taking into account the observations of melt expulsion from high speed photography, is presented for the prediction of laser drilled hole volume. The results indicate that the laser melting regime of the continuous wave laser-material interactions can be extended for drilling of materials, expanding the applications of these widely used lasers for flexible manufacturing. Keywords: ultrasonic vibrations; laser processing; laser drilling; melt expulsion; material removal
\end{abstract}

\footnotetext{
*Corresponding author. Tel.: +1 (405) 744-5830; E-mail: sandip.harimkar@okstate.edu
} 


\section{Introduction}

Pulsed laser drilling, in the laser-material interaction regime of surface melting, is commonly used for machining of $0.5-3 \mathrm{~mm}$ holes in a range of applications, as described in Dahotre and Harimkar (2008). The drilling of sub-1 mm cooling holes in the aerospace components is one of the most of important applications of the pulsed laser drilling and is discussed by French et al. (2003) . The laser drilling process involves irradiation of high intensity pulses that cause surface melting and evaporation at the surface of the melt film. Zhang and Faghri (1999) described that while some material removal occurs by surface evaporation, the dominant mechanism of material removal remains the melt expulsion during laser drilling. Wagner (1974) reported that the melt expulsion is a direct result of evaporation induced recoil pressure on the surface of the melt. When the pressure on the surface of the melt film exceeds the surface tension forces, the melt is pushed radially out, creating a hole by melt expulsion. Assist gases are often used to facilitate the melt expulsion during laser drilling. As Low et al. (2002) discussed, the efficiency of material removal (drilling rate) and the quality of drilled holes depend on the dynamics of the melt flow during laser drilling. Significant efforts have been made to improve the material removal rates and quality of holes during laser drilling. Chen et al. (1996) studied the effect of the peak power and the pulse format on the quality of the laser drilled holes. Low et al. (2000) investigated the effect of assist gas $\left(\mathrm{O}_{2}, \mathrm{Ar}, \mathrm{N}_{2}\right.$, and Air) on the thickness and geometry of the surface spatter formed during laser drilling and reported a significant reduction in spatter thickness in the case of $\mathrm{O}_{2}$ assist gas. It has also been demonstrated by Low et al. (2001) that the material ejection processes during laser drilling can be effectively controlled by temporal pulse train modulation for improving the material removal rate and quality of laser drilled holes. Lau et al. (1994) and Yue et al. (1996) also reported that the simultaneous application of ultrasonic 
vibrations during pulsed laser drilling improve the material removal and quality of laser drilled holes. With this approach of ultrasonic vibrations-aided pulsed laser drilling, about $20 \%$ increase in hole depth and about 30\% reduction in heat affected zone were reported by Lau et al. (1994) for aluminum matrix composites. However, even with these advances, laser drilling of large aspect-ratio holes with acceptable surface quality and reproducibility is still a challenge in adopting the technology for wider applications.

Continuous wave $(\mathrm{CW})$ laser surface melting, with steady state melting conditions reached at sufficiently high laser scanning velocities, results in the formation of well-defined resolidified bead on the surface. A continuous laser irradiation at a spot (i.e. stationary irradiation without scanning) on the surface also forms a well-defined melt pool, albeit with some surface rippling in some cases. These characteristics are very useful for surface modification of materials, and hence, continuous wave lasers are most appropriate for laser surface engineering applications as described in Ion (2005). The continuous wave lasers are also used in cutting applications where the assist gases expel the melt from the bottom of the cutting front/kerf. However, the use of continuous wave lasers, even with the presence of assist gases, in material drilling applications is limited. Recently, it has been observed by Alavi and Harimkar (2015a) that the simultaneous application of ultrasonic vibrations $(20 \mathrm{kHz})$ during continuous wave $\mathrm{CO}_{2}$ laser surface melting of stainless steel destabilizes the melt film and facilitates the melt expulsion. The melt expulsion resulted in the formation of well-defined craters with resolidified surface films. The laser surface melting experiments under the influence of ultrasonic vibrations were conducted for the laser power of $900 \mathrm{~W}$, laser irradiation times in the range of $0.35-0.45 \mathrm{~s}$, and the working distance (i.e. the distance between the laser head and the surface of the sample) of about $50 \mathrm{~mm}$. It has also been shown that the melt expulsion, in the form of sideways melt 
flow and droplet ejection, initiates when the critical melt film thickness is reached. The observation of melt expulsion during laser surface melting under the influence of ultrasonic vibrations presents a unique possibility of laser drilling with a continuous wave laser. The schematic showing the melt expulsion and hole formation during the ultrasonic vibrationsassisted continuous wave laser surface drilling is shown in Fig. 1.

The preliminary laser drilling experiments, reported by Alavi and Harimkar (2015b), have shown that the high aspect ratio holes can be drilled by reducing the working distance to about $15 \mathrm{~mm}$ for the similar laser processing and ultrasonic vibration parameters . It has also been observed that the ultrasonic vibration parameter, especially the vibration displacement, for the given ultrasonic frequency $(20 \mathrm{kHz})$ influences the geometric parameters of the laser drilled holes. In contrast to earlier investigations by Lau et al. (1994) and Yue et al. (1996) where ultrasonic vibrations were simultaneous applied during pulsed laser drilling (a well-established laser drilling process in itself), the proposed ultrasonic vibration-assisted continuous wave laser drilling extends the energy-efficient laser melting (no drilling) regime for laser drilling applications and enables continuous (instead of discontinuous pulsed) drilling of materials. Since continuous and pulsed wave laser outputs result in different laser-material interactions (primarily surface melting for continuous wave lasers; melting with extensive surface evaporation, generation of recoil pressure, and use of assist gas for pulsed lasers), direct comparison between continuous wave and pulsed laser machining/drilling is difficult. However, performing laser drilling in CW mode offers benefits related to energy/process efficiency and quality of machined surfaces. The pulsed laser drilling is performed with a very high peak power (up to $20 \mathrm{~kW}$ ) but low pulse repetition rates with long pulse off times as described in Roos (1980) The material surface cools very fast during this pulse off time, i.e. the surface needs to reheated/remelted 
again during each subsequent pulse to create melt expulsion as reported by Dahotre and Harimkar (2008). In continuous wave laser drilling under the influence of ultrasonic vibrations, the material removal is primarily in melting regime and sufficiently low power $(950 \mathrm{~W}$ in this case) continuous output is enough to facilitate melt expulsion. Furthermore, there are no off times in continuous wave laser drilling, so the melting is continuous (i.e. no intermittent cooling as in case of pulsed laser drilling) and performed in much shorter time. With efficient material removal under the influence of ultrasonic vibrations, the proposed continuous wave laser drilling is likely to offer benefits related to material removal rate and machined surface quality compared to conventional pulsed laser drilling. With the widespread use of continuous wave $\mathrm{CO}_{2}$ lasers in industry, the proposed laser drilling approach is likely to expand the applications of these lasers for flexible manufacturing.

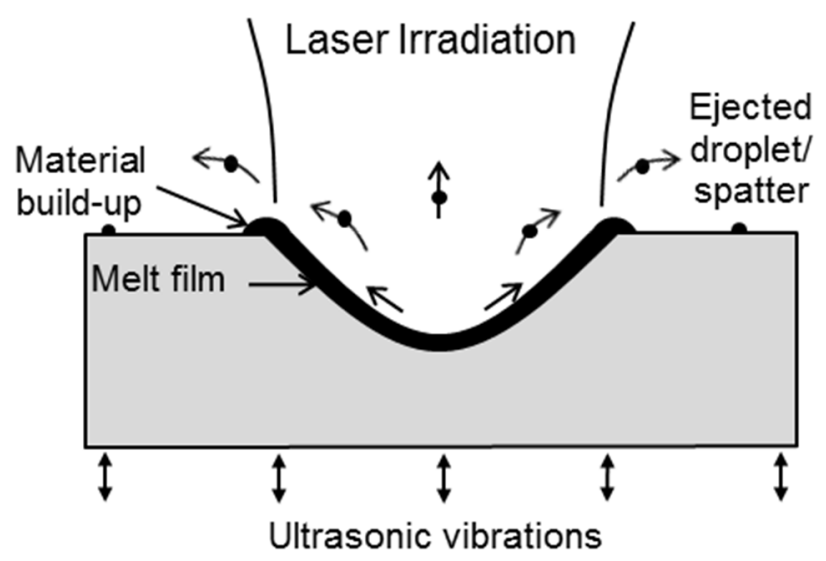

Fig. 1 Schematic of the melt expulsion in the form of upward melt flow and droplet ejection leading to hole formation during ultrasonic vibration-assisted laser surface melting.

While the preliminary studies have established the possibility of laser drilling with the proposed ultrasonic vibrations assisted-laser surface melting, it becomes important to establish the mechanisms of laser drilling under the influence of ultrasonic vibrations and investigate the 
evolution of geometric and quality aspects of the laser drilled holes with the laser irradiation time. In this paper, high speed photography is used to trace the sequence of processes, leading to formation of hole with the laser surface melting under the influence of ultrasonic vibrations (laser power of $950 \mathrm{~W}$, working distance of $15 \mathrm{~mm}$, ultrasonic vibration frequency of $20 \mathrm{kHz}$, and vibration displacement of $23 \mu \mathrm{m})$. Also, the results of detailed and systematic investigations on the evolution of geometric parameters (hole diameter, depth, aspect ratio, taper angle, and material removal rate) and quality parameters (build-up material at the hole rim, recast layer thickness on the hole walls, microstructure in recast layer, and heat affected zones) with the laser irradiation time in the range of $0.05-1.25 \mathrm{~s}$ (for the given specific laser processing and ultrasonic vibration parameters) are presented. A two-dimensional finite element model (heat transfer) based on critical time of melt expulsion observed from high speed photography is proposed for the prediction of material removal volume during laser drilling under the influence of ultrasonic vibrations. The predictions of the laser drilled hole volumes from the heat transfer model were compared with the experimental results for the investigated laser irradiation times.

\section{Experimental procedure}

The ultrasonic vibration-assisted laser surface drilling setup consisted of a continuous wave (cw) $\mathrm{CO}_{2}$ laser (Ferranti, Manchester, UK), a ultrasonic power supply, and a 13-mm diameter threaded titanium alloy probe/horn (Sonics \& Materials, Inc, Newtown, CT). The experiments were performed on $3.5 \mathrm{~mm}$ thick AISI 316 stainless steel specimens $(17.45 \% \mathrm{Cr}, 11.81 \% \mathrm{Ni}$, $2.5 \% \mathrm{Mo}, 0.05 \% \mathrm{C}, 1.35 \% \mathrm{Mn}, 0.68 \% \mathrm{Si}, 0.011 \% \mathrm{~S}, 0.047 \% \mathrm{P}$, and balance Fe by weight). Each steel specimen, surface finished by polishing using 400 grit $\mathrm{SiC}$ papers followed by sand blasting, was screwed on the threaded ultrasonic probe. The schematic of the experimental set-up 
is shown in Fig. 2. The laser surface melting was performed with a laser power of $950 \mathrm{~W}$ and working distance of $15 \mathrm{~mm}$ for a range of laser irradiation times: $0.05,0.10,0.20,0.25,0.35$, 0.75 , and $1.25 \mathrm{~s}$. The ultrasonic probe was vibrated (vibrations perpendicular to the specimen surface) with a vibration frequency of $20 \mathrm{kHz}$ and vibration displacement of $23 \mu \mathrm{m}$ (corresponding to ultrasonic power output of 20\%) during laser surface melting. The ultrasonic vibrations for this system are generated by piezoelectric lead zirconate titanate (PZT) crystals. A three-dimensional optical surface profiler (Nanovea, Irvine, CA) was used to measure the buildup volume of the material around the laser drilled hole periphery. A scanning electron microscope was used (JEOL Ltd, Tokyo, Japan) to characterize the surface and cross-sectional features of the laser drilled specimens. An image processing software, Image J, was used to measure the geometric and quality features of the laser drilled holes from the SEM micrographs. A high speed camera (X-StreamVISION; XS-4, IDT) was used to image the processes in early stages of laser drilling. To capture the illuminated droplets and melt pool (due to laser light irradiation), the exposure time was set at $22 \mu \mathrm{s}$, and the images were recorded with 8000 frames/s and image size of $480 \times 320$ pixels. 


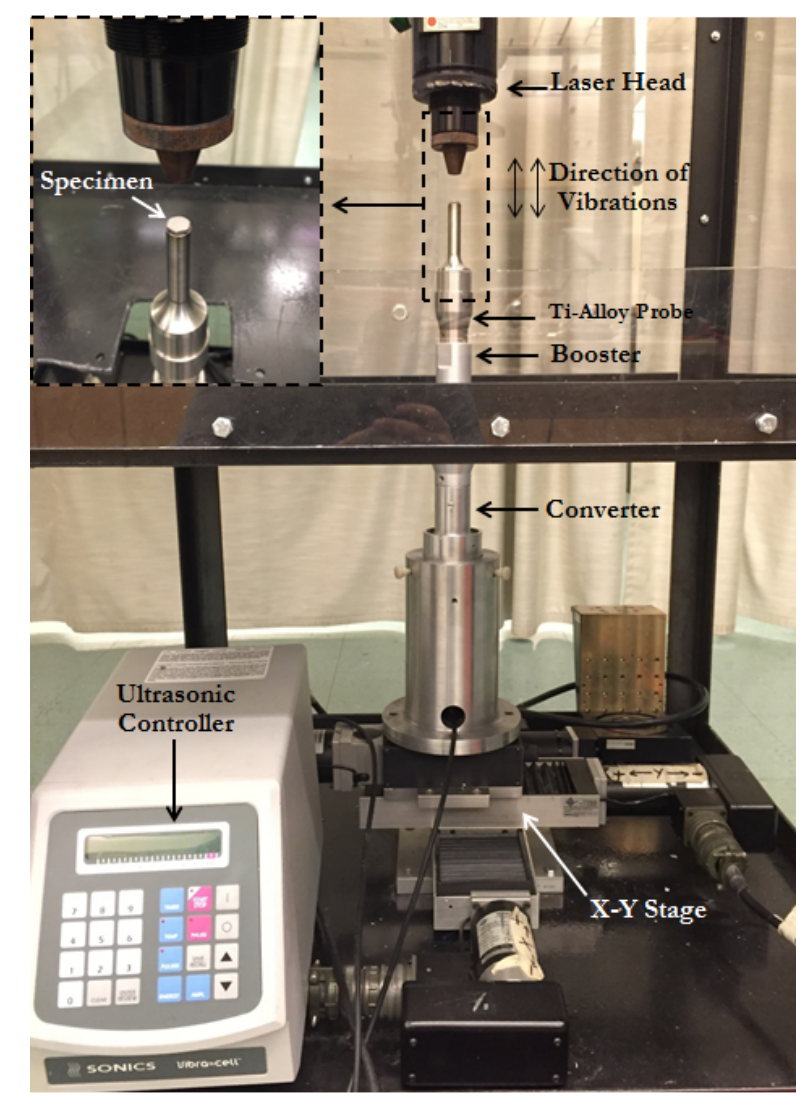

Fig. 2 Ultrasonic vibration-assisted laser surface processing setup.

\section{Results and discussion}

\subsection{High speed camera photography}

The preliminary studies reported earlier showed that continuous wave laser surface melting with a stationary beam resulted in the formation of well-defined resolidified regions on the surface of stainless steel samples. The simultaneous application of ultrasonic vibrations (of frequency 20 $\mathrm{kHz}$ ) during laser surface melting resulted in the melt expulsion in the form of lateral/sideways melt flow and droplet ejection from the laser irradiated surface, forming well-defined hole. To investigate the underlying mechanisms of material removal and hole formation due to ultrasonic vibrations assisted laser melting, high speed photography images during the process were captured. The sequence of frames captured during laser surface melting with the given laser 
processing (950 W, $15 \mathrm{~mm}$ working distance) and ultrasonic vibration parameters $(20 \mathrm{kHz}, 23$ $\mu \mathrm{m}$ vibration displacement) are presented in Fig. 3. The first three frames in this figure (Fig. 3ac) are the adjoining frames separated by time $0.125 \mathrm{~ms}$; these frames, showing the appearance of brighter spot on the surface, indicate the first signs of laser interaction with the material. With the continued laser irradiation, the surface of the material eventually melts and forms a well-defined melt pool; the size of the melt pool increases with time (Fig. 3d). The melt pool also shows the brighter outer rim, indicating the build-up of material due to lateral/sideways flow of material in the early stages of hole formation (Fig. 3d-e). Eventually, the melt pool gets destabilized leading to the ejection of a droplet from the center of the melt pool (Fig. 3e). It appears that the melt pool must reach a critical size/volume before the droplet ejection starts. Based on these high speed camera images, the droplet ejection initiates at about 2-2.125 ms after the first appearance of laser interaction with the material (i.e. appearance of the brighter spot on the surface). The brighter rim is also seen in the frames adjoining the frame showing first droplet ejection, indicating continued build-up of material at the periphery of the hole. The continued laser irradiation results in the ejection of a stream of droplets, advancing the drilling front and forming a deep hole. The angular trajectory of the ejected droplets can also be traced from the high speed camera images. In the early stages of drilling when the hole is shallow, the droplets are ejected in over a wider range of angular distribution. For the total laser irradiation time of $0.25 \mathrm{~s}$, it was observed that the trajectory angles of the ejected droplets were $57^{\circ}, 20^{\circ}, 7.5^{\circ}$, and $6.5^{\circ}$ at times of $12.5,100,196.75$, and $250 \mathrm{~ms}$, respectively. 

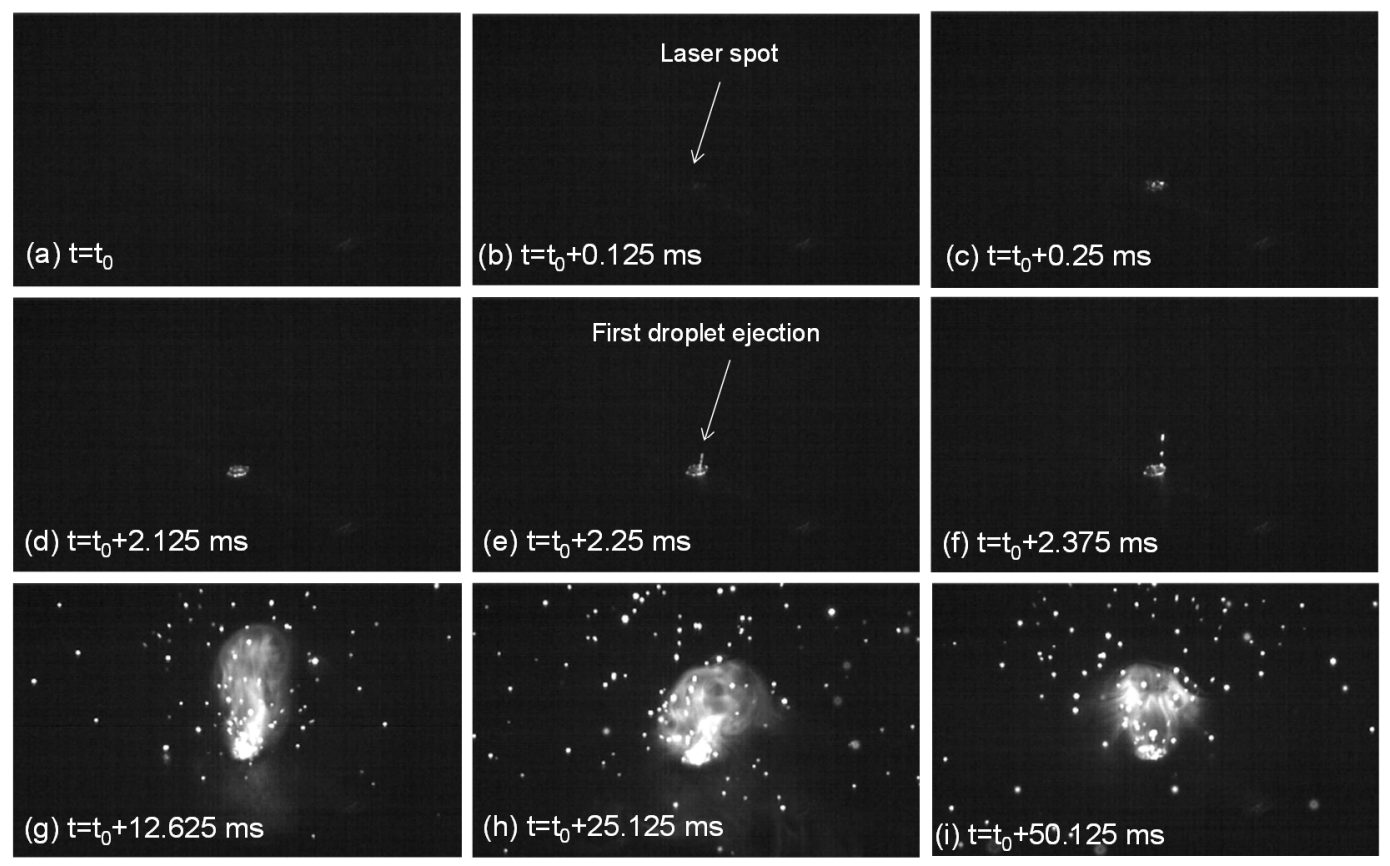

Fig. 3 High speed camera images showing the sequence of events during hole formation with the ultrasonic vibration-assisted laser surface melting.

\subsection{Geometric aspects}

SEM micrographs from the surface and cross-sections of the holes laser drilled with increasing laser irradiation time ( 0.05 to $1.25 \mathrm{~s})$ using the ultrasonic vibration-assisted laser surface melting are presented in Fig. 4. For the laser irradiation times up to $0.35 \mathrm{~s}$, it can be seen that the laser drilled holes are well defined with very good circularity and straightness (Fig. 4(a-e)). It appears that the material removal by droplet ejection is much more uniform for shorter irradiation times. To investigate the possibilities of drilling deeper holes, the experiments were also conducted for longer irradiation times of 0.75 and $1.25 \mathrm{~s}$. The SEM images from the surfaces of the holes drilled using these laser irradiation times also showed very good circularity at the surface (Fig. 4(f-g)). The cross sectional images indicate that deeper holes were actually formed with longer irradiation times, but the resolidification of the ejected droplets closes the holes giving lower 
effective depths. The SEM micrograph from $0.75 \mathrm{~s}$ shows that the hole is first closed just above the bottom of the hole (Fig. 4(f)). The continued laser irradiation causes further droplet ejection (probably from the resolidified region above the bottom of the hole) and solidification on the walls giving non-uniform hole diameter along the depth of the hole. The narrowing of the hole due to resolidification of droplets on the wall can be clearly seen for the sample with laser irradiated with $0.75 \mathrm{~s}$. The hole closing at multiple locations along the depth can happen for longer laser irradiation times, as shown in Fig. 4(g) for the laser irradiation time of $1.25 \mathrm{~s}$. It has been reported that in the conventional laser drilling also the molten material can be expelled out effectively in some cases and results in closed hole formation. It has been proposed that an extra assist gas pressure at the final stage of the drilling ejects the remaining molten material out of the hole, as described by Rodden et al. (2000).

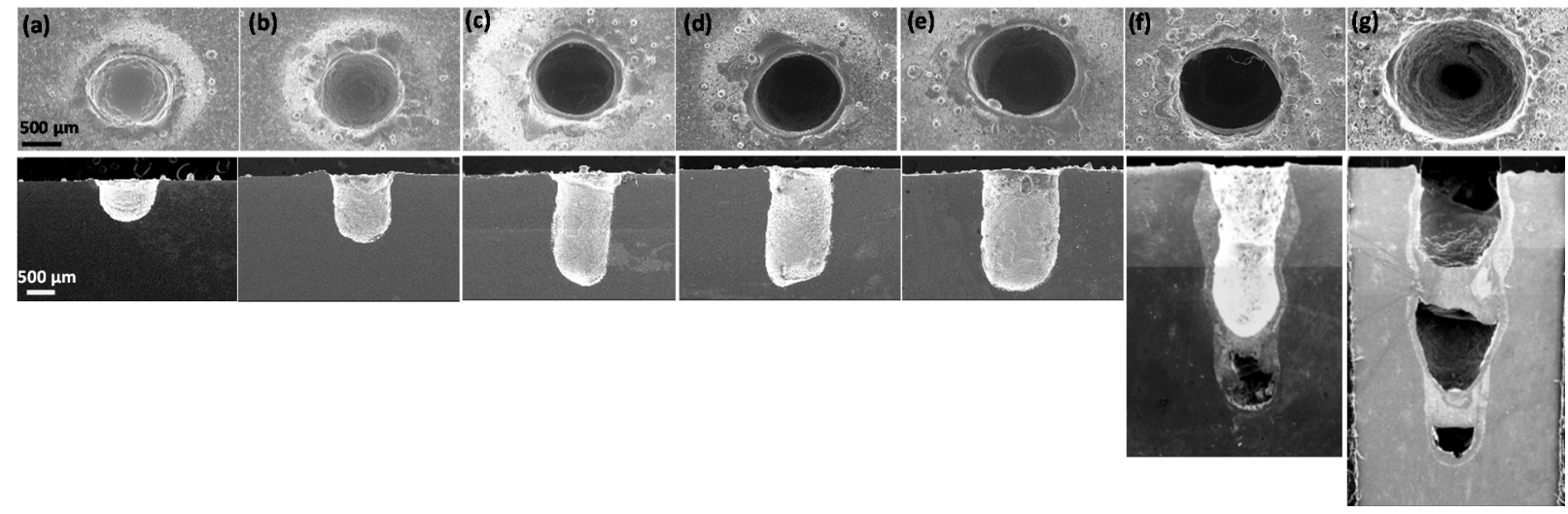

Fig. 4 SEM images from the surface and cross-sections of the laser drilled holes for laser irradiation times of: (a) $0.05 \mathrm{~s},(\mathrm{~b}) 0.1 \mathrm{~s},(\mathrm{c}) 0.2 \mathrm{~s}$, (d) $0.25 \mathrm{~s}$, (e) $0.35 \mathrm{~s}$, (f) $0.75 \mathrm{~s}$, and (g) $1.25 \mathrm{~s}$. (laser processing parameters: $950 \mathrm{~W}$ power and $15 \mathrm{~mm}$ working distance; ultrasonic vibration parameters: $20 \mathrm{kHz}$ frequency and $23 \mu \mathrm{m}$ vibration displacement).

The variation of diameter (at the surface) and depth of the laser drilled holes with laser irradiation time is presented in Fig. 5(a). The hole diameter at the surface increases slowly, but nearly linearly, with increasing laser irradiation time. The initial diameter of the hole is 
determined by the critical volume of melt for the droplet ejection under the influence of ultrasonic vibrations. After the initiation of droplet ejection, the melt front will continue to advance down the hole with continued laser irradiation. The sides of the holes can still melt due to irradiation with trailing edges of energy distribution in the laser beam, increasing the hole diameter with increasing laser irradiation time. For the investigated laser processing and ultrasonic vibration parameters, the hole diameter in the range of about $1.25-1.75 \mathrm{~mm}$ was observed. The depth of the laser drilled hole increases with increasing laser irradiation time. Note that the shortest laser irradiation time investigated in this study was $0.05 \mathrm{~s}$. The high speed camera images showed that the melt pool remains stable for $2.125 \mathrm{~ms}$, indicating that the no hole condition exists for the shorter duration of laser irradiation time. The hole depth increases nearly linearly at a very high rate (drilling rate in $\mathrm{mm} / \mathrm{s}$ ) up to the laser irradiation time of about 0.2 $0.25 \mathrm{~s}$. The drilling rate then progressively slows down with further increase in laser irradiation time. Similar trend was also observed for the mass loss, which corresponds to the material removed in the laser drilling process (Fig. 5(b)). The calculated volumetric material removal rate as a function of laser irradiation time is also plotted in Fig. 5(b). Clearly, the material removal rate decreases almost linearly with increasing laser irradiation time. The drilling rate or the material removal rate during laser surface melting under the simultaneous influence of ultrasonic vibrations is directly linked with the droplet ejection during the process. It appears that, for shallow holes formed with shorter laser irradiation times, the droplets are ejected in all the directions. The high speed camera images showed that the angular trajectory of the droplet ejection extends over a large angle. As the hole depth increases, the distribution of the angular trajectory of the droplets ejected from the bottom of the hole is limited by the geometry of the deep holes. For deeper holes, only the droplets ejected nearly vertically escape from the holes 
contributing to the material removal. The droplets ejected at an angle impinge on the side walls and resolidify, causing local narrowing of the hole along the depth as observed from the SEM images. The sideways ejection of the droplets does not contribute to the material removal, slowing down the drilling rate. With the investigated laser processing and ultrasonic vibration parameters, straight holes with diameter of $1.25-1.75 \mathrm{~mm}$ and depth up to about 2-2.5 $\mathrm{mm}$ can be easily drilled in stainless steel. The deeper holes with the depth of about 4-5 mm drilled with the similar processing parameters, but longer laser irradiation times, were associated with closed cavities along the hole depth due to resolidification of expelled melt. It seems that higher intensity ultrasonic vibrations (higher vibration displacement and frequency) are likely to facilitate efficient vertical ejection of the melt droplets for drilling deeper holes. It is worth mentioning that the maximum material removal rate in ultrasonic vibration-assisted laser drilling ( $\left.450 \mathrm{~mm}^{3} / \mathrm{min}\right)$ is significantly higher than that reported for conventional laser drilling (100 $\mathrm{mm}^{3} / \mathrm{min}$ ) in Ion (2005). 

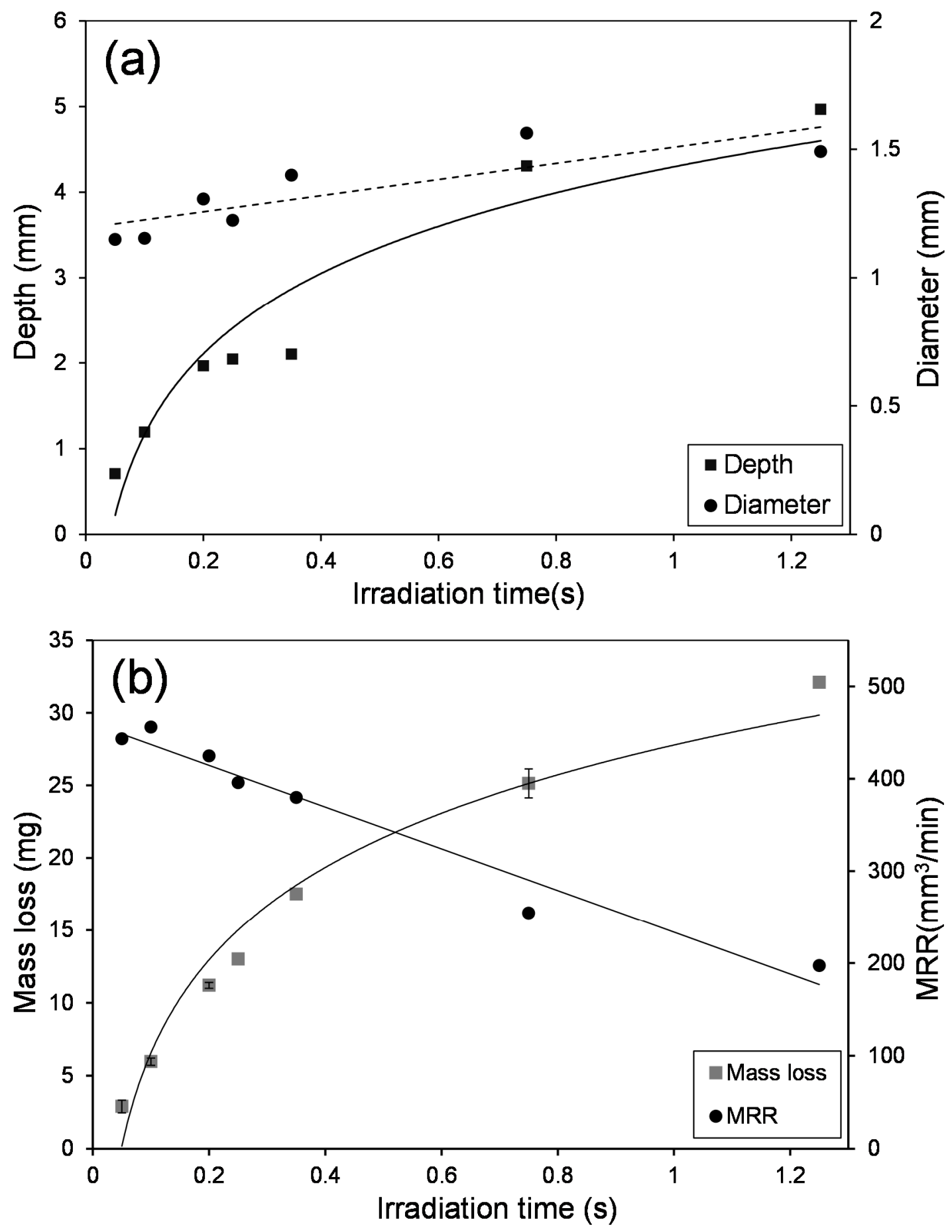

Fig. 5 (a) Variation of depth and diameter of the laser drilled holes, and (b) variation of mass loss and material removal rate (MRR) with laser irradiation time for the ultrasonic vibration-assisted laser drilling. 
The variation of hole aspect ratio and taper angle with laser irradiation time is plotted in Fig. 6(a). The hole aspect ratio increases with increasing laser irradiation corresponding to increasing depth of the hole. The hole aspect ratio was about 1.5 for the straight holes drilled with the laser irradiation time up to $0.35 \mathrm{~s}$. The higher aspect ratio of 2.5-3.5 was observed for the deeper holes drilled with laser irradiation time of $0.75-1.25 \mathrm{~s}$; note that these holes exhibited closed cavities as discussed earlier. The hole taper angle was calculated as follows:

$$
\text { Hole taper angle (degree) }=\frac{d_{i}-d_{o}}{2 t_{h}} \times \frac{180}{2 \pi}
$$

where $d_{i}$ is the diameter of the hole at the entrance, $d_{o}$ is the diameter of the hole at $200 \mu \mathrm{m}$ from bottom of the hole, and $t_{h}$ is the depth of the hole. The taper angle of the holes decreases with increasing laser irradiation time (i.e. with increasing depth of the holes). The taper angle is very high for shallow holes, but decreases to about $2-4^{\circ}$ at intermediate laser irradiation time for welldefined holes. Even though the deeper holes (drilled with laser irradiation time of 0.75-1.25 s) showed very low calculated taper angle, the hole diameter is not uniform along the depth and the holes exhibited closed cavities along the depth. The general trend of decreasing hole taper with depth/thickness is also observed for conventional pulsed laser drilling, as described by Yeo et al. (1994). However, much higher taper angles (up to $10^{\circ}$ ) have been reported for conventional laser drilling techniques by Ion (2005). 

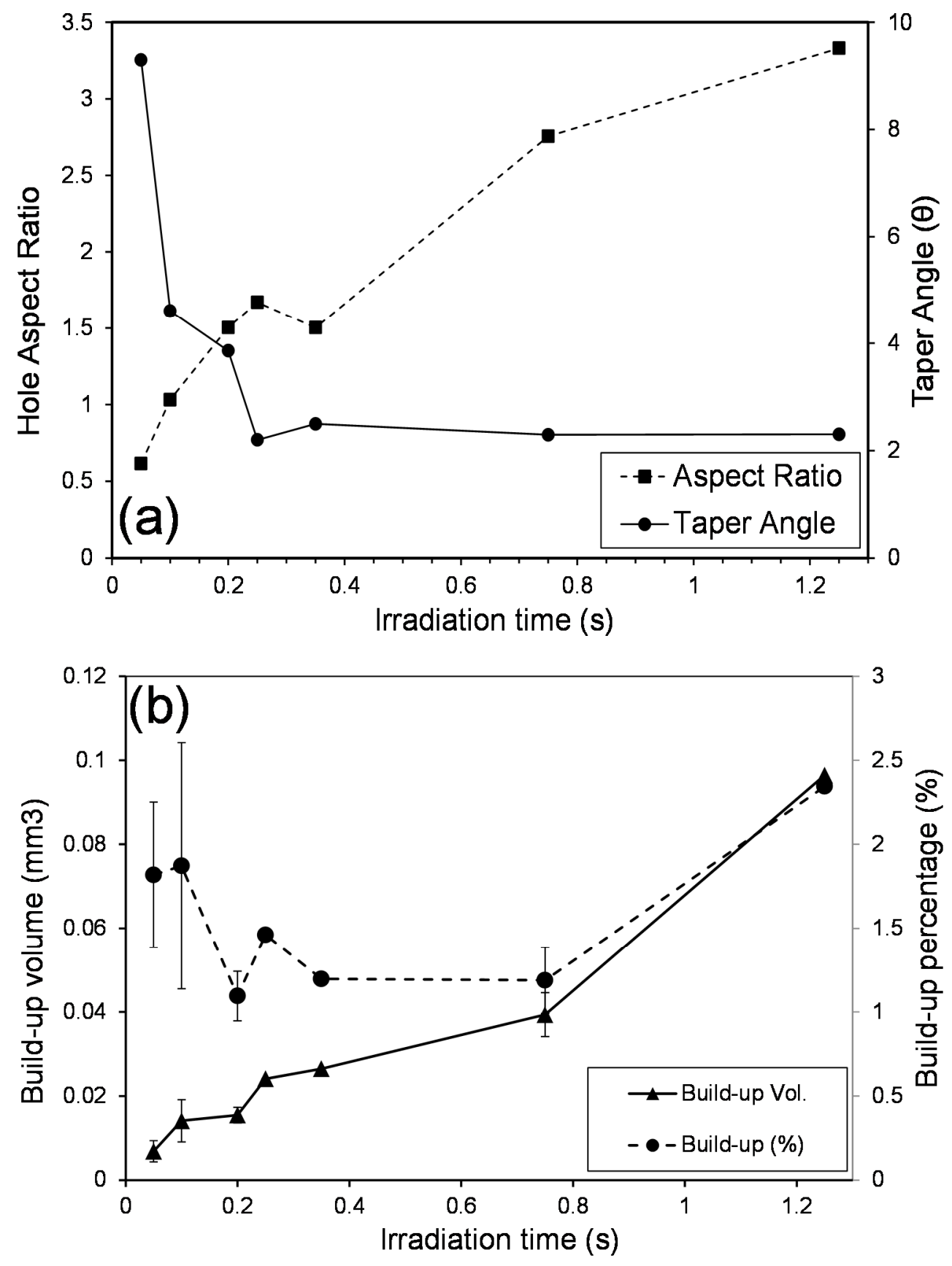

Fig. 6 (a) Variation of hole aspect ratio and taper angle of laser drilled holes, and (b) variation of build-up volume and percentage with laser irradiation time for the ultrasonic vibration-assisted laser drilling.

\subsection{Quality aspects:}


The SEM micrographs presented in Fig. 4 also show that holes laser drilled with the ultrasonic vibration-assisted laser surface melting are associated with typical defects of laser drilling. These micrographs show distinct material build-up near the rim of the holes, spatter on the surface, heat affected zones, and recast layer on the walls of the laser drilled holes. For the given laser processing and ultrasonic vibration parameters, the quality aspects of the laser drilled holes are significantly influenced by the laser irradiation time.

Fig. 7 presents the surface profiles from the laser drilled specimens showing material build-up near hole rims and spatter around the hole. The high speed camera images also show the appearance of brighter rim on the irradiated surface, indicating the formation of such build-up material. The material build-up near the rim of the hole is primarily due to lateral flow of melt outside the crater under the influence of ultrasonic vibrations. The material build-up is somewhat irregular, and the height of the build-up is not uniform along the rim of the hole. The measurement of the build-up volume using surface profilometry shows that the build-up material volume actually increases with increasing laser irradiation time, but the volume of build-up material in terms of percentage of total hole volume remained in the range of about $1-2.5 \%$ of the volume of the laser drilled holes at all the laser irradiation times. The observation indicates that the build-up material increases with increasing depth of the hole due to resolidification of ejected droplets on the initial build material. This is consistent with the observation based on angular trajectory of the ejected droplets. The droplets ejected nearly vertically from the bottom of the deeper holes are likely to fall and redeposit near the initial build up, increasing the amount of build-up material. 


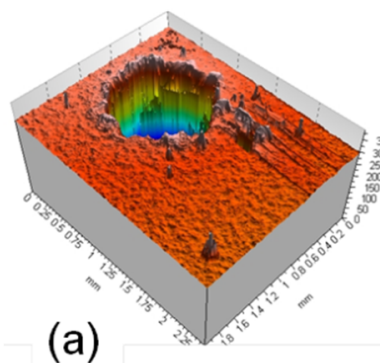

(a)
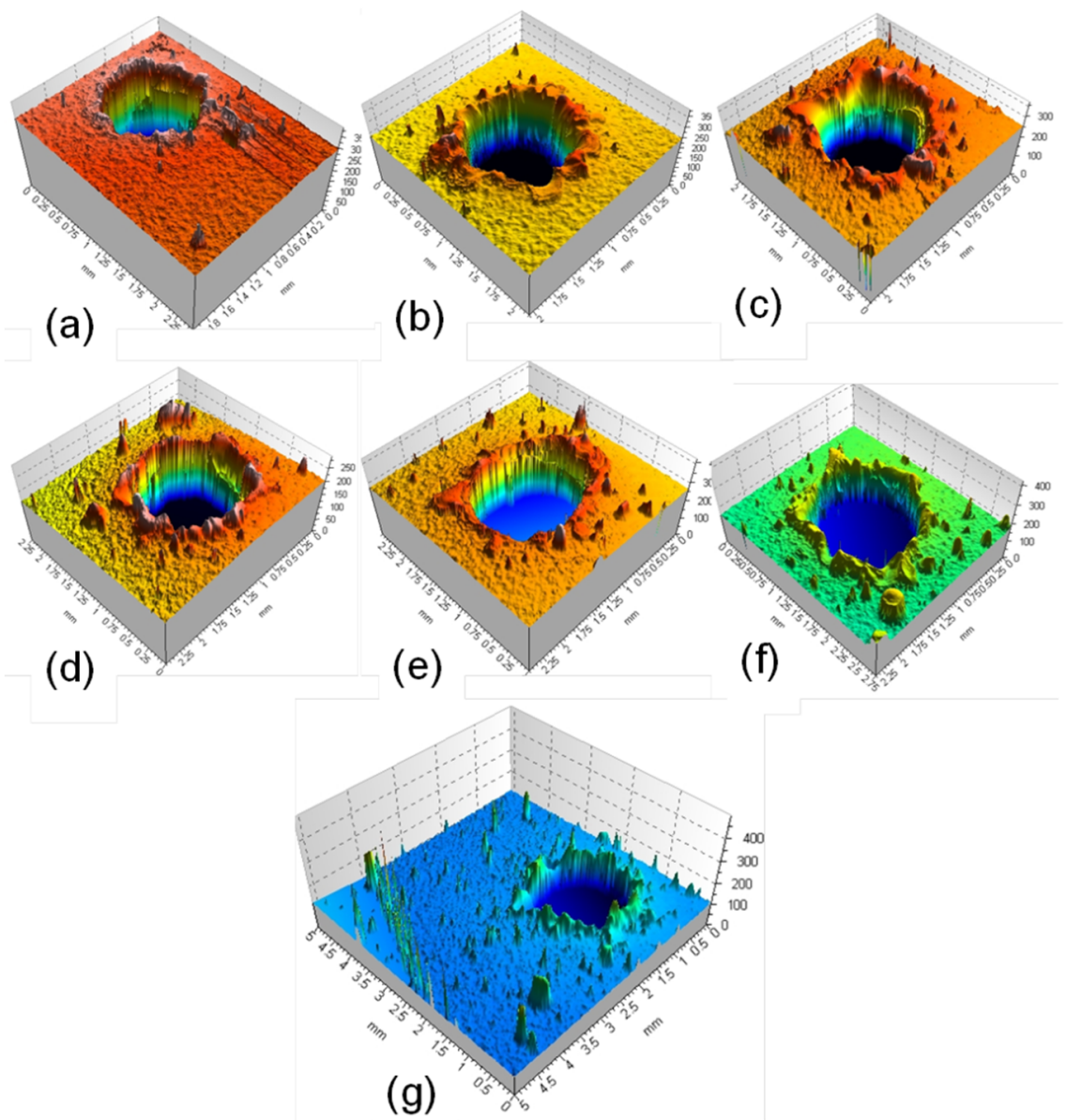

Fig. 7 Three-dimensional profiles from the surfaces of the laser drilled specimens for laser irradiation times of: (a) $0.05 \mathrm{~s}$, (b) $0.1 \mathrm{~s}$, (c) $0.2 \mathrm{~s}$, (d) $0.25 \mathrm{~s}$, (e) $0.35 \mathrm{~s}$, (f) $0.75 \mathrm{~s}$, and (g) $1.25 \mathrm{~s}$. (laser processing parameters: $950 \mathrm{~W}$ power and $15 \mathrm{~mm}$ working distance; ultrasonic vibration parameters: $20 \mathrm{kHz}$ frequency and $23 \mu \mathrm{m}$ vibration displacement).

The surface SEM images (Fig. 4) and the surface profiles (Fig. 7) of the laser drilled samples also show the presence of spatter on the surface due to resolidification of ejected droplets. The surfaces of the samples with shallower holes are relatively cleaner, and the amount of spatter increases with increasing the depth of hole, corresponding to the increasing laser irradiation time. It appears that the range (distance travelled) and angular distribution of the ejected melt droplets trajectory are large for shallower holes, yielding cleaner surfaces (i.e. the droplets fall and resolidify away from the hole). Most of the spatter on the surface for deeper holes is accumulated 
near the rim of holes, indicating that droplets ejected nearly vertically from the bottom of the deeper holes fall and resolidify closer to the hole rim and build-up material.

The SEM images (Fig. 4) from the surfaces of the laser drilled samples also show the presence of heat affected zone (regions with brighter contrast around the rim of the holes). The thickness of the heat affected zone at the surface increases with increasing laser irradiation time (corresponding to increasing depth of the hole), indicative of heat accumulation with the continued laser irradiation during laser drilling (Fig. 8).

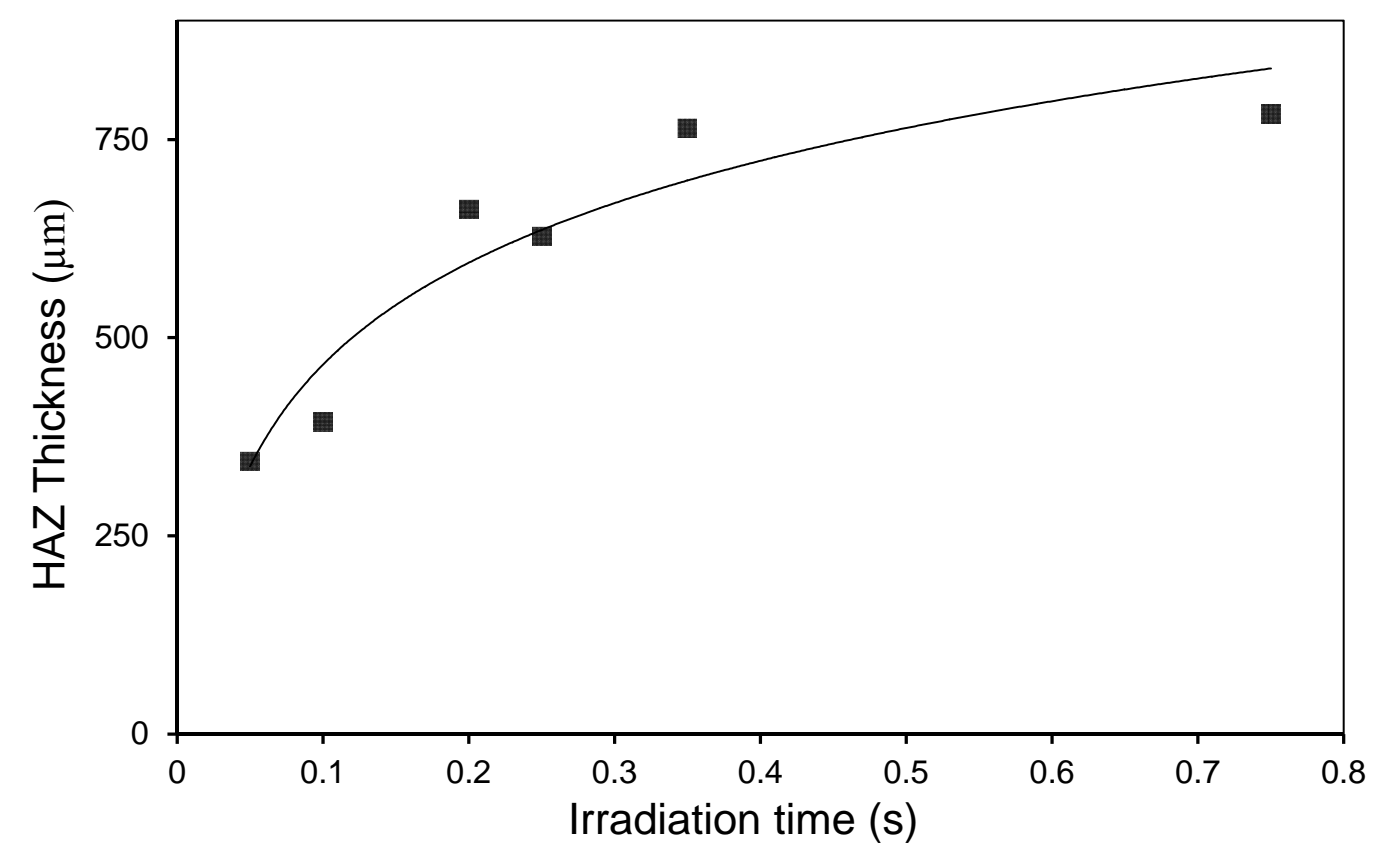

Fig. 8 Variation of thickness of heat affected zone (HAZ) at the surface of laser drilled specimens with laser irradiation time for the ultrasonic vibration-assisted laser drilling.

Significant recast layer was also observed on the walls of the holes drilled with all the laser irradiation times. A representative cross sectional SEM image from the etched sample (laser drilled with laser irradiation time of $0.35 \mathrm{~s}$ ) showing distinct recast layer on the hole walls is presented in Fig. 9(a). It can be seen that the recast layer thickness increases along the depth of the hole and is maximum at the bottom of the hole. The surface of hole walls are also rougher 
indicating resolidification of ejected droplets on the walls. A high magnification image of the recast layer from near the bottom of the hole is also presented in Fig. 9(b). It can be seen that the microstructure of the recast layer consisted of primarily columnar grains (with width of grains about $3.84 \pm 0.53 \mu \mathrm{m}$ ) growing from the substrate towards center of the molten cap at the drilling front. The cellular grains with grain size of $4.37 \pm 1.46 \mu \mathrm{m}$ are observed near the surface of the recast layer. It appears that the cellular grains are mostly formed in the recast layer near the bottom of the holes possibly due to resolidification of last remaining melt pool which could not be ejected due to very low volume. The grain structure is primarily columnar in the recast layer formed near the top of the holes (Fig. 9(c)).
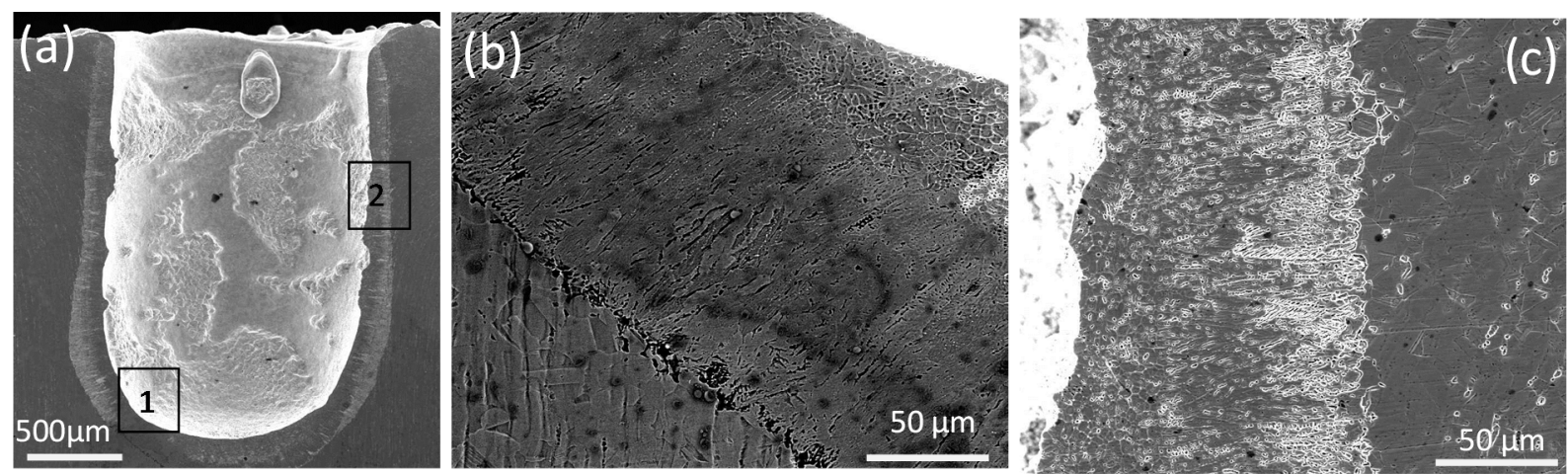

Fig. 9 (a) SEM micrograph showing recast layer on the walls of laser drilled holes, and (b-c) higher magnification microstructures of recast layers from regions near the bottom and entrance of the holes, identified as regions 1 and 2 in (a), respectively.

The variation of recast layer with depth of the holes drilled with laser irradiation times of 0.05 , $0.35,0.75$ and $1.25 \mathrm{~s}$ is shown in Fig. 10. For the straight holes drilled with shorter laser irradiation times ( 0.05 and $0.35 \mathrm{~s})$, the recast layer is up to $65 \mu \mathrm{m}$ at the hole entrance and about $65-240 \mu \mathrm{m}$ at the bottom of the hole. For deeper holes drilled with laser irradiation times of 0.75 and $1.25 \mathrm{~s}$, the laser drilling was unstable and resulted in build-up of material on the hole walls and formation of closed cavities along the hole depth. The recast layer was relatively thicker 
$(\sim 100-180 \mu \mathrm{m})$ for these holes along with localized build-up of about $0.5 \mathrm{~mm}$ at some locations along the depth. The locations along the depth where hole closes due to resolidification of expelled material are also marked in the Fig. 10.

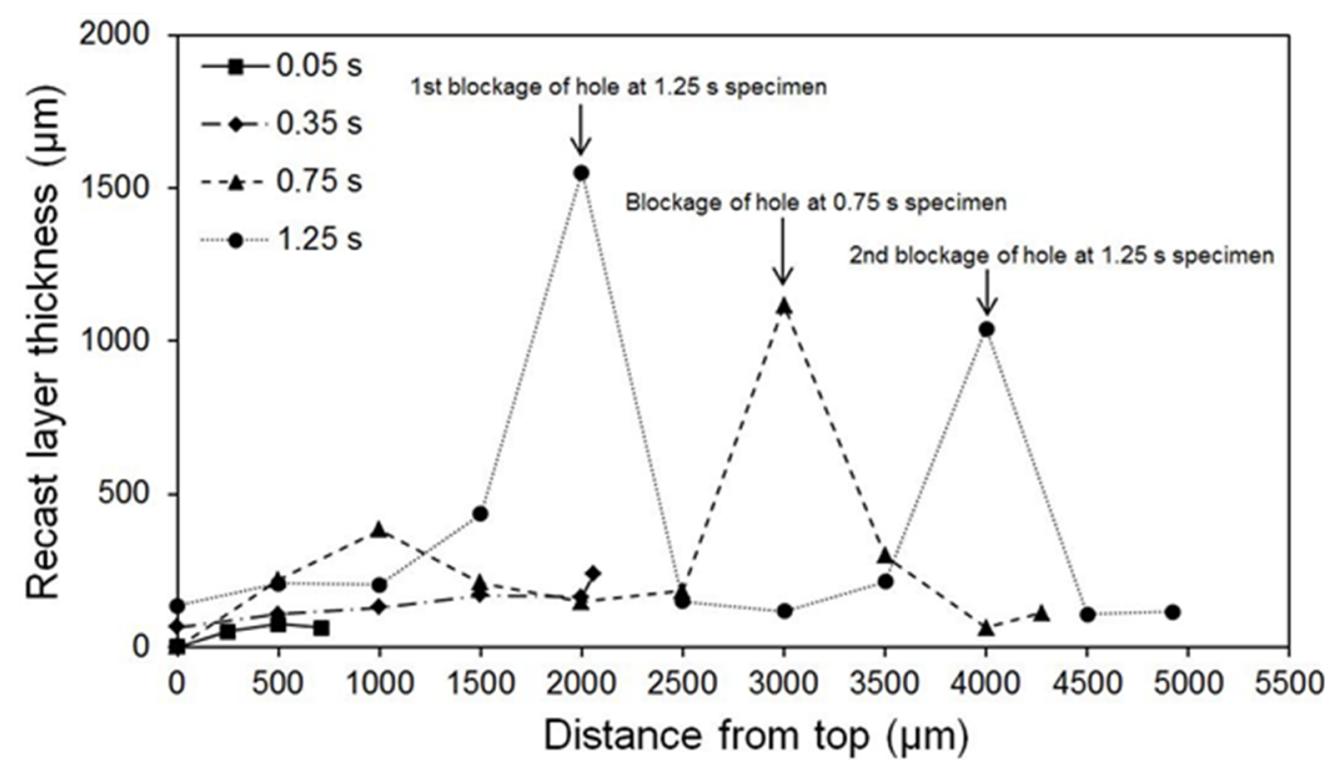

Fig. 10 Variation of recast layer thickness on the hole walls with distance from the surface along the depth of the hole for different laser irradiation times. The locations of localized build-up of material along the hole depth are also indicated.

\subsection{Finite element analysis}

A multi-step two-dimensional finite element modeling (FEM) approach, taking into account the observations of melt expulsion from the high speed photography, was developed to analyze temperature distributions and hole formation during the laser surface melting of the AISI 316 stainless steel specimens. Commercially available COMSOL Multiphysics ${ }^{\circledR}$ software was selected to solve the heat transfer equations. The specimen geometry was rectangular with dimensions of $12 \mathrm{~mm}$ for top and bottom surface and $3.5 \mathrm{~mm}$ for the two sides. The top surface of the geometry irradiated with the laser beam was subjected to heat flux, natural convection, and radiation boundary conditions. The bottom surface of the geometry was considered insulating, 
and the two sides were subjected to natural convection and radiation heat transfer boundary conditions. Minimum and maximum mesh size was $0.001 \mathrm{~mm}$ and $0.1 \mathrm{~mm}$, respectively. Following assumptions were considered:

a) Laser beam has a Gaussian distribution of the energy (TEM $\left.{ }_{00}\right)$.

b) Material loss due to surface evaporation and recoil pressure is not involved, and the material removal during the ultrasonic vibration-assisted laser melting occurs in molten state.

c) Multiple reflections of laser beam in the drilling cavity are negligible.

The material properties and initial boundary conditions for the heat transfer model are listed in Tables I and II. The procedure for calculating volume of material removed for the formation of holes during ultrasonic-vibration assisted laser surface melting is discussed below.

Step I: In the first step, the heat transfer model was solved with the given boundary conditions to determine the temperature distribution in the sample and the laser irradiation time for the initiation of melting at the surface. Fig. 11(a) shows the temperature distribution in the sample when the surface of the material reaches melting point corresponding to laser irradiation time of $1.53 \mathrm{~ms}$. The evolution of surface temperature as a function of laser irradiation time is also in Fig. 12. 
Table I Materials properties and model parameters employed in 2D heat transfer finite element analysis.

\begin{tabular}{|c|c|c|c|c|c|}
\hline Parameter & $\begin{array}{c}\text { Symbo } \\
1\end{array}$ & \multicolumn{3}{|c|}{ Value (AISI 316 stainless steel) } & Ref. \\
\hline $\begin{array}{l}\text { Density } \\
\left(\mathrm{kg} / \mathrm{m}^{3}\right)\end{array}$ & $\rho$ & $\left\{\begin{array}{l}8084-0.4209 \times T-3.894 \times \\
7433-0.0393 \times T-1.801 \times\end{array}\right.$ & $\begin{array}{l}-5 \times T^{2} \\
-4 \times T^{2}\end{array}$ & $\begin{array}{l}T<1700 K \\
T \geq 1750 K\end{array}$ & $\begin{array}{l}\text { Bobko } \\
\text { v et al. } \\
\text { (2008) }\end{array}$ \\
\hline $\begin{array}{l}\text { Heat } \\
\text { capacity } \\
(\mathrm{J} / \mathrm{kg} . \mathrm{K})\end{array}$ & $C_{p}$ & \multicolumn{3}{|l|}{$\begin{array}{l}462+0.134 \times T \\
775\end{array}$} & $\begin{array}{l}\text { Bobko } \\
\text { v et al. } \\
\text { (2008) }\end{array}$ \\
\hline $\begin{array}{l}\text { Thermal } \\
\text { conductivit } \\
\text { y }(\mathrm{W} / \mathrm{m} \cdot \mathrm{K}) \text {, }\end{array}$ & $k$ & \multicolumn{3}{|c|}{$\begin{array}{cc}14.6-33.7 & 273<T<1753 \\
120 & T>1753\end{array}$} & $\begin{array}{c}\text { Deng } \\
\text { and } \\
\text { Murak } \\
\text { awa } \\
\text { (2006) }\end{array}$ \\
\hline $\begin{array}{l}\text { Melting } \\
\text { temperature } \\
(\mathrm{K})\end{array}$ & $T_{m}$ & \multicolumn{3}{|c|}{1753} & \\
\hline $\begin{array}{c}\text { Stefan- } \\
\text { Boltzmann } \\
\text { constant } \\
\left(\mathrm{W} / \mathrm{m}^{2} \cdot \mathrm{K}^{4}\right)\end{array}$ & $\sigma$ & \multicolumn{3}{|c|}{$5.67 \times 10^{-8}$} & $\begin{array}{l}\text { Pinker } \\
\text { ton } \\
\text { and } \mathrm{Li} \\
(2004)\end{array}$ \\
\hline $\begin{array}{l}\text { Absorption } \\
\text { coefficient }\end{array}$ & $A$ & \multicolumn{3}{|l|}{0.15} & \\
\hline Emissivity & $\varepsilon$ & \multicolumn{3}{|l|}{0.4} & $\begin{array}{l}\text { Amine } \\
\text { et al. } \\
(2014)\end{array}$ \\
\hline $\begin{array}{l}\text { Standard } \\
\text { deviation of } \\
\text { laser beam } \\
(\mathrm{mm})\end{array}$ & $\varphi$ & \multicolumn{3}{|c|}{ Beam diameter $/ 6$} & $\begin{array}{c}\text { Vora } \\
\text { and } \\
\text { Dahotr } \\
\text { e } \\
(2015)\end{array}$ \\
\hline
\end{tabular}

Step II: The high speed camera images indicated that the surface melting initiates and melt pool grows before the ejection of the melt droplets, indicating that critical volume of melt is required for the droplet ejection. The droplet ejection initiates at about $2.2 \mathrm{~ms}$ of laser irradiation. The FEM analysis in first step showed that surface melting initiates at about $1.53 \mathrm{~ms}$. The time interval of $0.67\left(\mathrm{t}_{1}\right)$ corresponds to the time taken for the initiation of first melt expulsion after 
the initiation of surface melting. Using the time for melt ejection of $2.2 \mathrm{~ms}$ (based on high speed camera), the FEM model was run to determine the temperature distribution and volume of molten material for droplet ejection. The Fig. 11(b) shows the temperature distribution and melting isotherm after laser irradiation for $2.2 \mathrm{~ms}$. Fig. 12 shows that the temperature at the surface of the melt reaches to about $1835 \mathrm{~K}$ at the laser irradiation time of $2.2 \mathrm{~ms}$. The depth and width of melting after this irradiation time are about $24 \mu \mathrm{m}$ and $439 \mu \mathrm{m}$, respectively. The corresponding melt volume $\left(V_{c}\right)$ at the $\mathrm{t}=2.2 \mathrm{~ms}$ is $1.82 \times 10^{6} \mu \mathrm{m}^{3}$.

Table II Boundary conditions employed in 2D heat transfer finite element analysis.

\begin{tabular}{|c|c|c|}
\hline $\begin{array}{c}\text { Boundary } \\
\text { Conditions }\end{array}$ & Equation & Ref. \\
\hline $\begin{array}{c}\text { Heat flux } \\
\text { (top boundary) }\end{array}$ & $\rho C_{p}\left[\frac{\partial T}{\partial t}\right]=k\left[\left(\frac{\partial^{2} T}{\partial x^{2}}\right)+\left(\frac{\partial^{2} T}{\partial y^{2}}\right)\right]$ & $\begin{array}{c}\text { Vora and } \\
\text { Dahotre } \\
(2015)\end{array}$ \\
\hline Natural \\
$\begin{array}{c}\text { convection and } \\
\text { radiation heat } \\
\text { transfer } \\
\text { (top and side } \\
\text { boundaries) }\end{array}$ & $-k\left[\left(\frac{\partial T}{\partial x}\right)+\left(\frac{\partial T}{\partial y}\right)\right]$ & $\begin{array}{c}\text { Vora and } \\
\text { Dahotre } \\
(2015)\end{array}$ \\
\hline $\begin{array}{c}\text { Laser power density } \\
\text { in }\end{array}$ & $=A P_{G a u}-\varepsilon \sigma\left[T^{4}-T_{0}{ }^{4}\right]-h\left[T-T_{0}\right]$ & \\
$\begin{array}{c}\text { Gaussian } \\
\text { distribution }\left(\mathrm{W} / \mathrm{m}^{2}\right)\end{array}$ & $P_{G a u}=\left(\frac{P}{\pi \varphi^{2}}\right) \times e^{\left(-\frac{\left(x-x_{0}\right)^{2}}{2 \varphi^{2}}\right)}$ & $\begin{array}{c}\text { Mazumder } \\
\text { and Steen } \\
(1980)\end{array}$ \\
\hline
\end{tabular}

Step III: In the next step, it was considered that the ejected material corresponding to first critical volume of melt is removed from the surface, and that the laser heating continues on the new surface (at melting point) to form the critical volume of melt for next droplet ejection. In this step, the volume of material corresponding to critical volume of melt was removed from the 
geometry, and new boundary conditions were applied to keep the temperature distribution developed in remaining of the specimen. Fig 11(c) shows the updated geometry and temperature distributions after removal of melt volume due to droplet ejection. It should be noted that the finite element analysis takes time of about $0.035 \mathrm{~s}$ for the stabilization of given temperature distribution in the sample and attain the domain temperature (corresponding to melting point) at the surface of updated geometry (Fig. 12).

Step IV: In the last step, the FEM analysis was conducted with laser irradiation on the updated geometry until the critical volume of melt is formed again. In contrast to the first step where the initial temperature of the irradiated surface and sample is room temperature, the surface of the updated geometry in this step is at melting temperature with temperature distributions in the sample. Other heat transfer boundary conditions such as surface convection and surface-toambient radiation applied to the surface in first step were also applied to the updated geometry in this last step. Fig. 11(d) shows the temperature distributions in the sample corresponding to the formation of critical melt volume in the updated geometry $(\mathrm{t}=2.56 \mathrm{~ms})$. The critical volume of melt is formed in the updated geometry after the time interval of $0.325 \mathrm{~ms}\left(\mathrm{t}_{2}\right)$ after the first melt expulsion. The temperature evolution at the surface in this step is also shown in Fig. 12. The surface of the melt reaches the temperature of about $1813 \mathrm{~K}$ at the end of this step. 

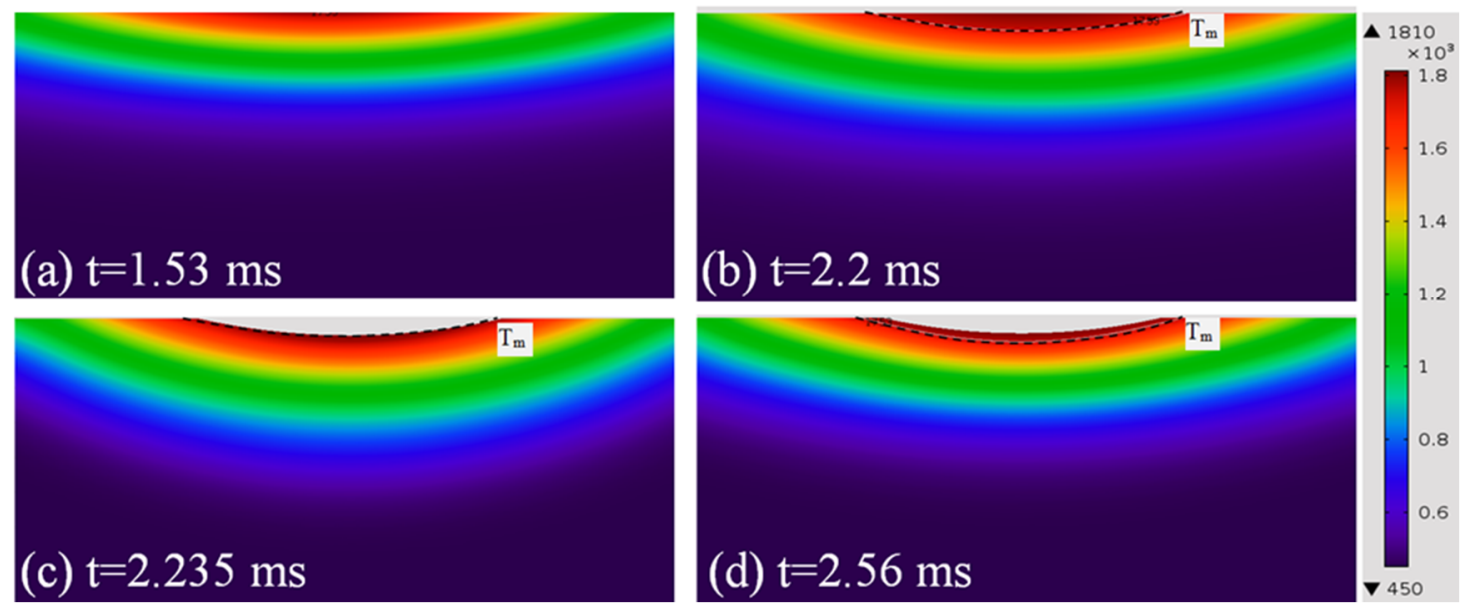

Fig. 11 Calculated temperature distributions in the cross section of the laser irradiated specimens at: (a) initiation of surface melting at $\mathrm{t}=1.53 \mathrm{~ms}$, (b) initiaton of melt ejection when the critical melt volume is formed at $\mathrm{t}=2.2 \mathrm{~ms}$, (c) updated geometry after removing the volume of melt corresponding the melt ejection volume, and (d) continued laser irradiation of updated geometry to form critical volume of melt again.

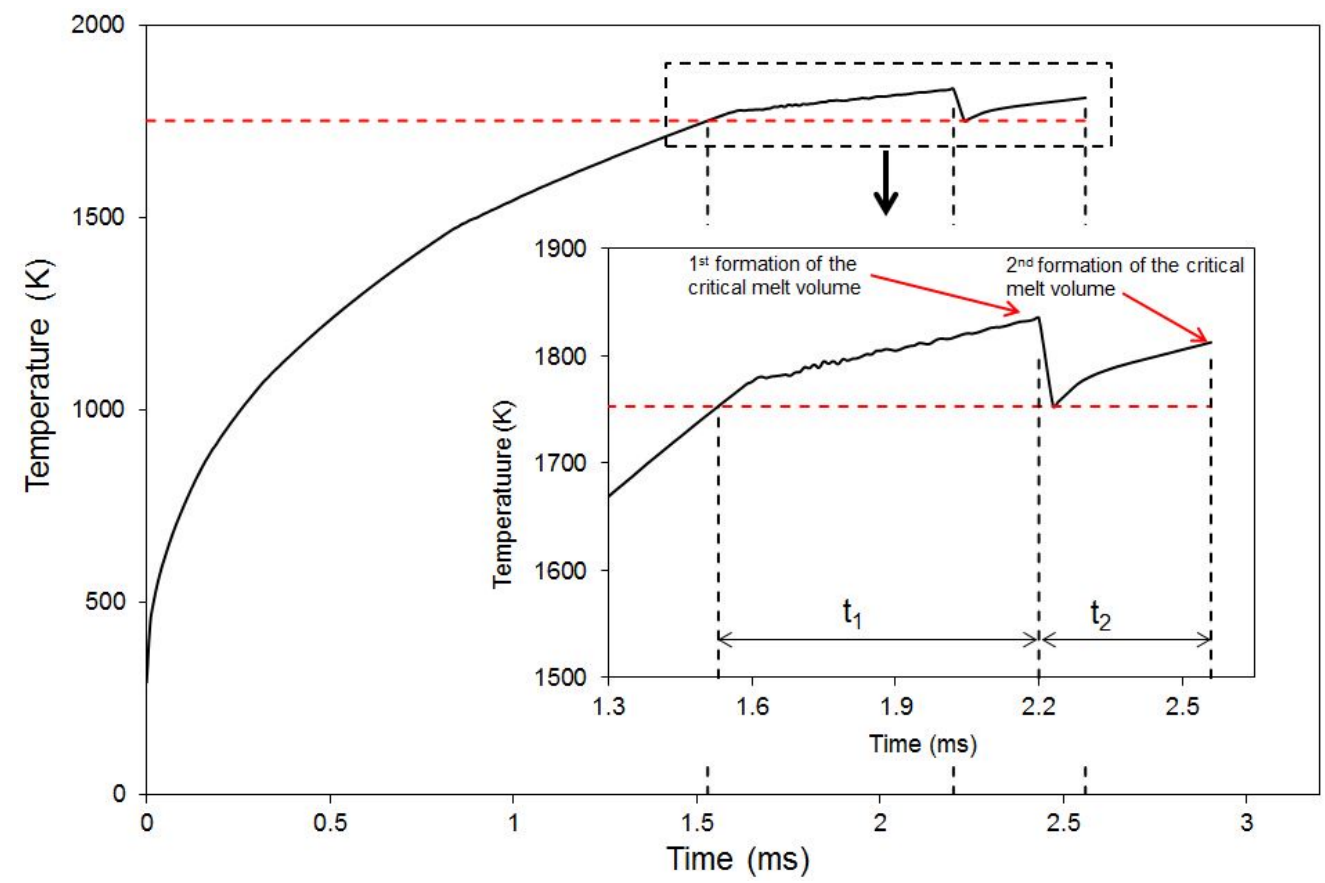

Fig. 12 Variation of surface temperature with irradiation time; the inset shows the details of temperature distributions near melting point indicating first and second formations of the critical melt volume for melt expulsion. 
Considering that material removal continues with repeated formation of critical volume and droplet ejection, the FEM analysis can be continued by updating the geometry for each melt expulsion during the entire duration of laser irradiation. However, this computational analysis will be too time intensive due to large number of steps involved (corresponding to number of melt expulsions during the entire duration of laser irradiation) and also due to time taken for the stabilization of temperature distribution after each melt expulsion (accounted by removing the melted region and updating the model geometry). As the surface temperature of the updated geometry (at melting point) and temperature distribution in the sample is not likely to change much for subsequent steps, the time interval for subsequent melt expulsions is likely to remain close to that taken for the second melt expulsion $\left(\mathrm{t}_{2}=0.325 \mathrm{~ms}\right)$. The hole volume can then be given by:

$$
V_{h}=\frac{t_{t}}{t_{2}} \times V_{c}
$$

where $t_{2}$ is the time for melt expulsion $\left(t_{2}=0.325 \mathrm{~ms}\right), t_{t}$ is the laser irradiation time after the first expulsion of the melt $\left[t_{t}=\right.$ total irradiation time $(t)$-melt initiation time $\left.\left(t_{i}=1.53 \mathrm{~ms}\right)\right]$, and $V_{c}$ is the critical volume of melt for melt expulsion.

The hole volumes predicted from the above FEM analysis were compared with experimental hole volumes for all laser irradiation times (Fig. 13). It can be seen that the predicted hole volume increases linearly with the laser irradiation time. Note that actual amount of material removed (mass loss) and depth of the hole increase linearly only up to the laser irradiation time of $0.35 \mathrm{~ms}$. Beyond this laser irradiation time (i.e. for deeper holes), the effects related to resolidification of ejected droplets on the walls of the holes and formation of closed cavities dominate and the laser drilling rate slows down. Similar trend is also observed for the 
variation of experimental hole volume with the laser irradiation time. The predicted hole volume shows close agreement, though with some underestimation, with the experimental value up to laser irradiation time of $0.35 \mathrm{~s}$. These are the conditions that resulted in the formation of straight holes with fairly good geometric and quality parameters. The FEM analysis overestimates the hole volume for the longer irradiation time $(0.75$ and $1.25 \mathrm{~s})$ because it doesn't account for the aforementioned effects. It must be noted that the proposed FEM analysis doesn't include the fluid dynamics, especially related to particle breaking of the laser melted pool, in the prediction of the laser drilled hole volumes. The breaking of the laser melted pool and ejection of melt droplets under the influence of ultrasonic vibrations is a very complex problem. In this study, the prediction of critical volume for melt expulsion from the FEM (thermal model) was made based on direct observations, especially the time to initiate melt expulsion, from high speed camera imaging. Similar melt expulsion criteria such as critical melt temperature are routinely used in the laser drilling/machining processes without the need of incorporating complex underlying fluid dynamics of melt film breaking in the FEM modeling. For example, in Vora and Dahotre (2015), the evaporation temperature was selected for material removal criteria during the updating the geometry.. Our results shows that once the melt expulsion time for laser melting under the influence of ultrasonic vibrations is established, the proposed FEM analysis can be readily used for the prediction of resultant hole volume, especially in the regime of irradiation time where sound/quality holes are obtained. 


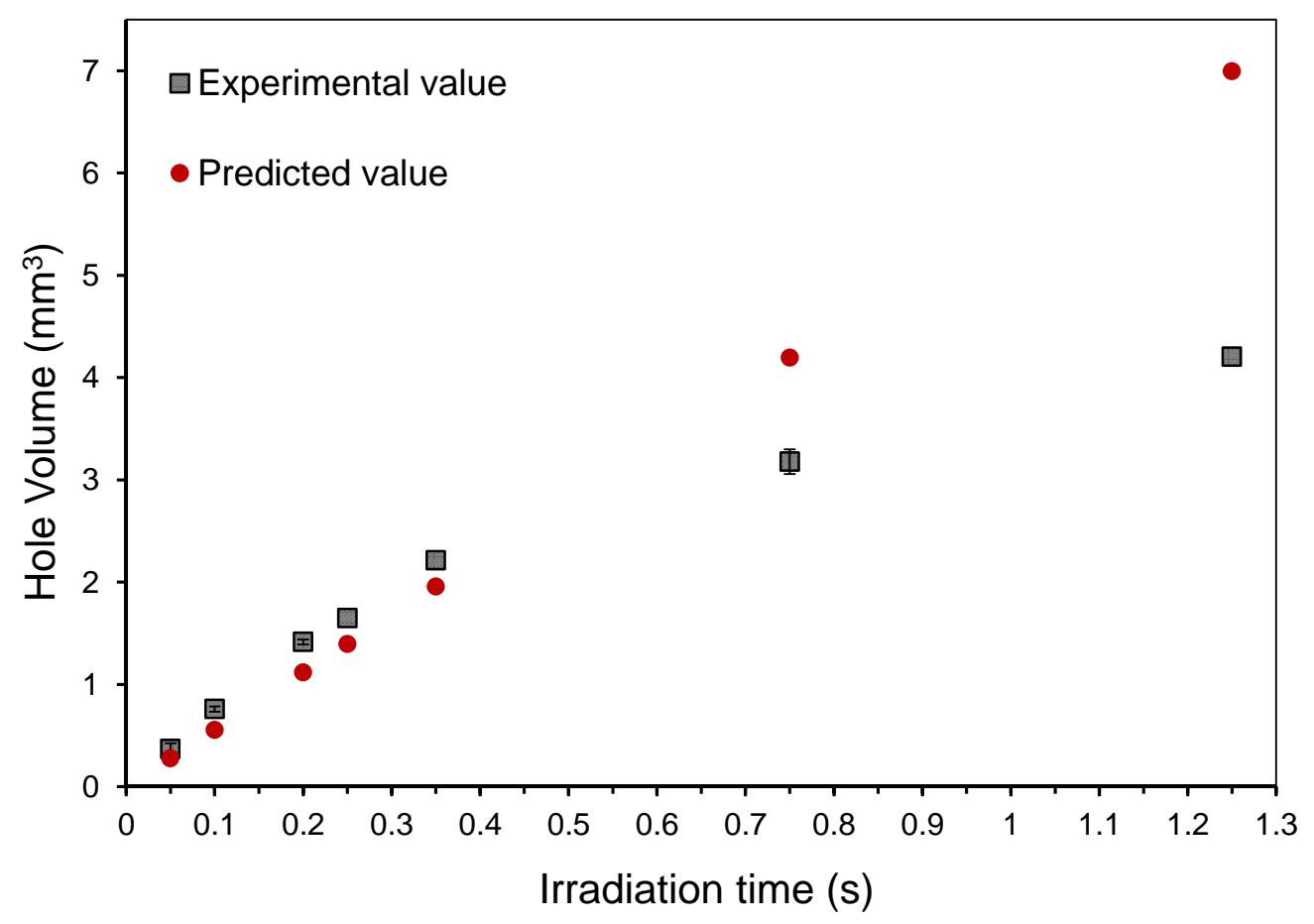

Fig. 13 Variation of experimental and predicted hole volume with laser irradiation time for the ultrasonic vibrationassisted laser drilling.

\section{Conclusions}

1. This paper systematically investigated the evolution of geometric features (hole depth, diameter, aspect ratio, and taper) and quality parameters (material build-up, spatter, recast layer thickness, and heat affected zone) of holes with laser irradiation time for the ultrasonic vibration-assisted $\mathrm{CW} \mathrm{CO} 2$ laser surface drilling (UVLD) of AISI 316 stainless steel. The UVLD process presents a great potential for the laser drilling of straight sub-2 $\mathrm{mm}$ diameter holes (with depth up to $5 \mathrm{~mm}$ ) in continuous wave laser melting regime.

2. The depth of the laser drilled holes increases almost linearly in the early stages (irradiation time up to $0.2-0.25 \mathrm{~s}$ ), the drilling rate then progressively decreases (irradiation time 0.25 $1.25 \mathrm{~s})$. Based on the analysis of angular trajectory distribution of ejected droplets, the observed trend is related to the resolidification of ejected droplets on the hole walls as the 
hole gets deeper (corresponding to increasing laser irradiation time). Straight holes with aspect ratio up to 3.5 and taper angle of about $2.3^{\circ}$ were successfully drilled with the UVLD of stainless steel.

3. The holes drilled with ultrasonic vibration-assisted laser drilling also exhibited typical quality defects such as build-up material at the hole rims, spatter of the surface, recast layer on hole walls, and heat affected zones. The amount or extent of these quality features generally increases with increasing laser irradiation time. While the laser drilled holes exhibited good straightness and circularity up to the laser irradiation time of $0.35 \mathrm{~s}$, the deeper hole holes formed with laser irradiation time of 0.75 and $1.25 \mathrm{~s}$ showed localized build-up of ejected droplets on the hole walls, resulting in localized narrowing and closure of the holes.

4. For the UVLD of AISI 316 stainless steel, the high speed camera images indicated that a critical volume of melt is required for the initiation of melt expulsion and hole formation under the influence of ultrasonic vibrations. The multi-step finite element analysis, taking into account the observations of melt expulsion from high speed photography, gives close prediction of laser drilled hole volume in the early stages of laser drilling (laser irradiation time up to $0.35 \mathrm{~s})$.

\section{Acknowledgements}

This material is based upon work supported by the National Science Foundation under Grant No. CMMI-1149079 


\section{References}

Alavi, S.H., Harimkar, S.P., 2015a. Melt expulsion during ultrasonic vibration-assisted laser surface processing of austenitic stainless steel. Ultrasonics 59, 21-30.

Alavi, S.H., Harimkar, S.P., 2015b. Ultrasonic Vibration-assisted Continuous Wave Laser Surface Drilling of Materials. Manufacturing Letters.

Amine, T., Newkirk, J.W., Liou, F., 2014. An investigation of the effect of direct metal deposition parameters on the characteristics of the deposited layers. Case Studies in Thermal Engineering 3, 21-34.

Bobkov, V., Fokin, L., Petrov, E., Popov, V., Rumiantsev, V., Savvatimsky, A., 2008. Thermophysical Properties of Materials for Nuclear Engineering: A Tutorial and Collection of Data. IAEA, Vienna.

Chen, X., Lotshaw, W., Ortiz, A., Staver, P., Erikson, C., McLaughlin, M., Rockstroh, T., 1996. Laser drilling of advanced materials: effects of peak power, pulse format, and wavelength. Journal of laser Applications 8, 233-239.

Dahotre, N.B., Harimkar, S.P., 2008. Laser fabrication and machining of materials. Springer.

Deng, D., Murakawa, H., 2006. Numerical simulation of temperature field and residual stress in multi-pass welds in stainless steel pipe and comparison with experimental measurements. Computational materials science 37, 269-277.

French, P., Naeem, M., Watkins, K., 2003. Laser percussion drilling of aerospace material using a $10 \mathrm{~kW}$ peak power laser using a $400 \mu \mathrm{m}$ optical fibre delivery system. ICALEO 2003 proceedings, Jacksonville. LIA, Orlando, paper 503.

Ion, J., 2005. Laser processing of engineering materials: principles, procedure and industrial application. Butterworth-Heinemann. 
Lau, W., Yue, T., Wang, M., 1994. Ultrasonic-aided laser drilling of aluminium-based metal matrix composites. CIRP Annals-Manufacturing Technology 43, 177-180.

Low, D., Li, L., Byrd, P., 2001. The influence of temporal pulse train modulation during laser percussion drilling. Optics and lasers in engineering 35, 149-164.

Low, D., Li, L., Corfe, A., 2000. Effects of assist gas on the physical characteristics of spatter during laser percussion drilling of NIMONIC 263 alloy. Applied surface science 154, 689-695.

Low, D.K.Y., Li, L., Byrd, P.J., 2002. Hydrodynamic Physical Modeling of Laser Drilling. Journal of Manufacturing Science and Engineering 124, 852-862.

Mazumder, J., Steen, W., 1980. Heat transfer model for CW laser material processing. Journal of Applied Physics 51, 941-947.

Pinkerton, A., Li, L., 2004. An analytical model of energy distribution in laser direct metal deposition. Proceedings of the Institution of Mechanical Engineers, Part B: Journal of Engineering Manufacture 218, 363-374.

Rodden, W., Kudeshia, S., Hand, D., Jones, J., 2000. The use of assist gas in the precision laser drilling of titanium, Proceedings of the ICALEO, pp. 41-50.

Roos, S.O., 1980. Laser drilling with different pulse shapes. Journal of Applied Physics 51, 5061-5063.

Vora, H.D., Dahotre, N.B., 2015. Surface topography in three-dimensional laser machining of structural alumina. Journal of Manufacturing Processes 19, 49-58.

Wagner, R., 1974. Laser drilling mechanics. Journal of Applied Physics 45, 4631-4637.

Yeo, C., Tam, S., Jana, S., Lau, M.W., 1994. A technical review of the laser drilling of aerospace materials. Journal of Materials Processing Technology 42, 15-49. 
Yue, T., Chan, T., Man, H., Lau, W., 1996. Analysis of ultrasonic-aided laser drilling using finite element method. CIRP Annals-Manufacturing Technology 45, 169-172.

Zhang, Y., Faghri, A., 1999. Vaporization, melting and heat conduction in the laser drilling process. International journal of heat and mass transfer 42, 1775-1790. 


\section{List of Tables:}

Table I Materials properties and model parameters employed in 2D heat transfer finite element analysis.

Table II Boundary conditions employed in 2D heat transfer finite element analysis. 


\section{List of Figures:}

Fig. 1 Schematic of the melt expulsion in the form of upward melt flow and droplet ejection leading to hole formation during ultrasonic vibration-assisted laser surface drilling.

Fig. 2 Ultrasonic vibration-assisted laser surface processing setup.

Fig. 3 High speed camera images showing the sequence of events during hole formation with the ultrasonic vibration-assisted laser surface drilling.

Fig. 4 SEM images from the surface and cross-sections of the laser drilled holes for laser irradiation times of: (a) $0.05 \mathrm{~s}$, (b) $0.1 \mathrm{~s}$, (c) $0.2 \mathrm{~s}$, (d) $0.25 \mathrm{~s}$, (e) $0.35 \mathrm{~s}$, (f) $0.75 \mathrm{~s}$, and (g) $1.25 \mathrm{~s}$. (laser processing parameters: $950 \mathrm{~W}$ power and $15 \mathrm{~mm}$ working distance; ultrasonic vibration parameters: $20 \mathrm{kHz}$ frequency and $23 \mu \mathrm{m}$ vibration displacement).

Fig. 5 (a) Variation of depth and diameter of the laser drilled holes, and (b) variation of mass loss and material removal rate (MRR) with laser irradiation time for the ultrasonic vibration-assisted laser drilling.

Fig. 6 (a) Variation of hole aspect ratio and taper angle of laser drilled holes, and (b) variation of build-up volume and percentage with laser irradiation time for the ultrasonic vibration-assisted laser drilling.

Fig. 7 Three-dimensional profiles from the surfaces of the laser drilled specimens for laser irradiation times of: (a) $0.05 \mathrm{~s}$, (b) $0.1 \mathrm{~s}$, (c) $0.2 \mathrm{~s}$, (d) $0.25 \mathrm{~s}$, (e) $0.35 \mathrm{~s}$, (f) $0.75 \mathrm{~s}$, and (g) $1.25 \mathrm{~s}$. (laser processing parameters: $950 \mathrm{~W}$ power and $15 \mathrm{~mm}$ working distance; ultrasonic vibration parameters: $20 \mathrm{kHz}$ frequency and $23 \mu \mathrm{m}$ vibration displacement).

Fig. 8 Variation of thickness of heat affected zone (HAZ) at the surface of laser drilled specimens with laser irradiation time for the ultrasonic vibration-assisted laser drilling. 
Fig. 9 (a) SEM micrograph showing recast layer on the walls of laser drilled holes, and (b-c) higher magnification microstructures of recast layers from regions near the bottom and entrance of the holes, identified as regions 1 and 2 in (a), respectively.

Fig. 10 Variation of recast layer thickness on the hole walls with distance from the surface along the depth of the hole for different laser irradiation times. The locations of localized build-up of material along the hole depth are also indicated.

Fig. 11 Calculated temperature distributions in the cross section of the laser irradiated specimens at: (a) initiation of surface melting at $\mathrm{t}=1.53 \mathrm{~ms}$, (b) initiaton of melt ejection when the critical melt volume is formed at $\mathrm{t}=2.2 \mathrm{~ms}$, (c) updated geometry after removing the volume of melt corresponding the melt ejection volume, and (d) continued laser irradiation of updated geometry to form critical volume of melt again.

Fig. 12 Variation of surface temperature with irradiation time; the inset shows the details of temperature distributions near melting point indicating first and second formations of the critical melt volume for melt expulsion.

Fig. 13 Variation of experimental and predicted hole volume with laser irradiation time for the ultrasonic vibration-assisted laser drilling. 